\title{
Theoretical calculations on conformations of bile-acid based dimers. Interactions with ibuprofen
}

\author{
Álvaro Antelo, Mercedes Álvarez Alcalde, Aida Jover, Francisco Meijide, and José \\ Vázquez Tato \\ Departamento de Química Física, Facultad de Ciencias, Universidad de Santiago de \\ Compostela, Avda. Alfonso X El Sabio s/n, 27002 Lugo, Spain,
}

\begin{abstract}
An AM1 semiempirical method (Gaussian 03) was used to perform molecular structure optimizations in gas phase of two tail-to-tail bile acid-based dimers by an isophthalic acid bridge. The method was also used to study the interactions with the potential guest ibuprofen with the idea of applicative results.
\end{abstract}

\section{Introduction}

Bile acids possessing a chiral molecular structure consisting of a facially amphiphilic steroid nucleus and a polar lateral chain have been used as suitable building supramolecular blocks ${ }^{1}$ and in molecular recognition. ${ }^{2}$ A variety of molecular frameworks, including natural products, have been utilized to design rigid pre-organized molecular systems to create clefts, cavities, and other types of binding surfaces. The idea of linking two cholic acid molecules to form an acyclic cleft was first reported by McKenna et $a .^{3}$ More recently, Kohmoto et $a l^{4}$ have synthesized a cleft-type host molecule possessing a cholic acid moiety as a pedant from the condensation of naphthalene-1,4,5,8-tetracarboxylic acid dianhydride with a $3 \alpha$-aminocholanoate derivative. Based on ${ }^{1} \mathrm{H}-\mathrm{NMR}$ spectrometric titration, this receptor was found to associate with 2,6-bis(hydroxymethyl)naphthalene with a binding constant of $91 \pm 9 \mathrm{M}^{-1}$ and a host-guest ratio of 1:1. It was observed that in the absence of guest, the host adopted two stable conformations at $213 \mathrm{~K}$. The cleft-type conformation of the host was induced by the inclusion of the 2,6-bis(hydroxymethyl)naphthalene molecule. The hydrogen bonding between the hydroxyl groups of host and guest was suggested as the

\footnotetext{
${ }^{1}$ Nonappa; Maitra U. Org. Biomol. Chem., 2008, 6, 657-669

${ }^{2}$ Wallimann, P.; Marti, T.; Fürer, A.; Diederich, F. Chem. Rev. 1997, 97, 1567-1608.

${ }^{3}$ McKenna, J.; McKenna, J. M.; Thornthwaite, D. W. J. Chem. Soc., Chem. Commun. 1977, 809.

${ }^{4}$ Kohmoto, S.; Sakayori, K.; Kishikawa, K.; Yamamoto, M. J. Chem. Soc., Perkin Trans. 2 1999, 833.
} 
driving force for the formation of the cleft-type structure. Kolehmainen et $a l^{5}$ synthesized lithocholic acid-based molecular clefts and investigated their conformational preferences and their $\mathrm{Ag}^{+}$-cation binding properties both experimentally by NMR measurements and theoretically by MO calculations. On the other hand, the cleft-dimer structural unit can serve as an artificial ion channel in order to attempt more sophisticated control of ionic flux across membranes. ${ }^{6}$

Taking also into account the possibility of encapsulating guests such as drug molecules within the internal 'cavities' of "tweezers", we have carried out theoretical studies on the conformation of the two bile acid-based dimers of Figure 1 and also on their interactions with the guest ibuprofen (see also Figure 1). The hosts represent potential biochemically interesting structures for molecular recognition via nonspecific hydrophobic binding forces and hydrogen bonding, and the guest, a very common pharmaceutical compound, presents groups capable of establishing both hydrogen bonds and hydrophobic interactions.
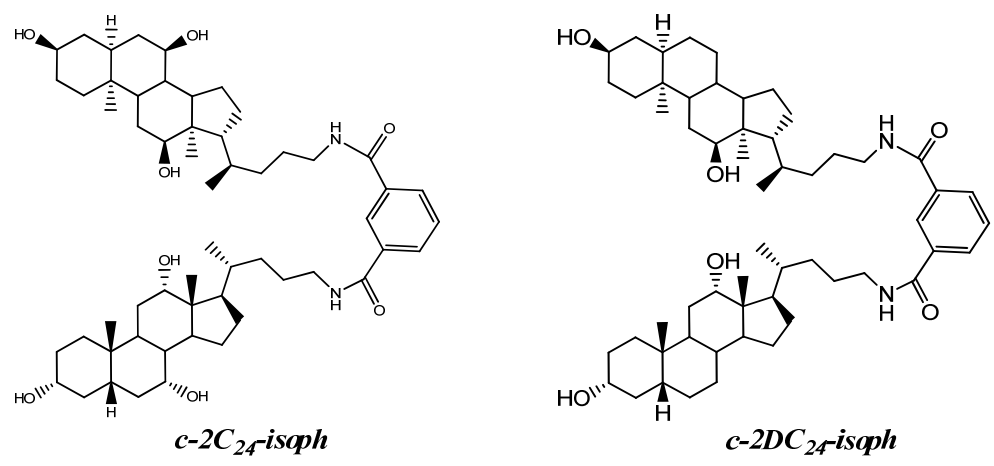

Figure 1.- Dimers used as hosts.
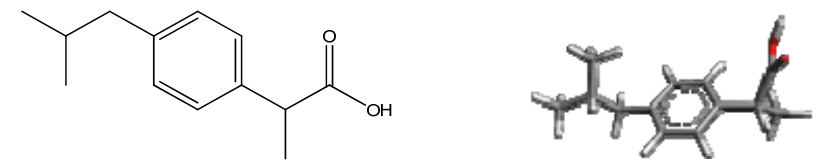

Figure 2.- Two representations of the ibuprofen molecule used as guest.

\section{Results on molecular modelling and discussion}

The conformations of the dimers were initially fully optimized at the semiempirical AM1 level on the $\mathrm{CESGA}^{7}$ workstation by using Gaussian 03 software. ${ }^{8}$ In

\footnotetext{
${ }^{5}$ Tamminen, J.; Kolehmainen, E.; Linnanto, J.; Salo, H.; Mänttäri, P. Magn. Res. Chem. 2000, $38,877$.

${ }^{6}$ Yoshii, M.; Yamamura, M.; Satake, A.; Kobuke, Y. Org. Biomol. Chem. 2004, 2, 2619 - 2623.

${ }^{7}$ The authors thank the CESGA computation centre for technical and software support.

${ }^{8}$ Gaussian 03, Revision A.1, M. J. Frisch, G. W. Trucks, H. B. Schlegel, G. E. Scuseria, M. A.
} 
view of the molecular structure of the compounds, three conformations have been explored: (i) fully extended steroid moieties, (ii) cleft-type conformation with their $\alpha$ faces mutually opposite, (iii) cleft-type conformation with their $\beta$ faces mutually opposite. The differences in energy between the analysed conformations for dimers $c$ $2 C_{24}$-isoph and $c-2 D C_{24}$-isoph (see Table 1) are quite small $\left(\approx 2 \mathrm{kcal} \mathrm{mol}^{-1}\right)$ and of the order of the semiempirical method errors. Therefore, it may be concluded that in the gas phase the dimers are flexible.

The minimum energy conformation for the host-guest complexes was obtained for the four conformations (Figures 3 and 4 for $2 C_{24}$-isoph and $c-2 D C_{24}$-isoph, respectively) resulting from the two cleft-type conformations of the dimer and the two (one inverted respect to the other) of the ibuprofen. Subtracting the energies of the host and the guest alone from those corresponding to the complexes in the analyzed conformations, the energies involved in the processes are obtained. Values are reported in Table 1.

Robb, J. R. Cheeseman, J. A. Montgomery, Jr., T. Vreven, K. N. Kudin, J. C. Burant, J. M. Millam, S. S. Iyengar, J. Tomasi, V. Barone, B. Mennucci, M. Cossi, G. Scalmani, N. Rega, G. A. Petersson, H. Nakatsuji, M. Hada, M. Ehara, K. Toyota, R. Fukuda, J. Hasegawa, M. Ishida, T. Nakajima, Y. Honda, O. Kitao, H. Nakai, M. Klene, X. Li, J. E. Knox, H. P. Hratchian, J. B. Cross, C. Adamo, J. Jaramillo, R. Gomperts, R. E. Stratmann, O. Yazyev, A. J. Austin, R. Cammi, C. Pomelli, J. W. Ochterski, P. Y. Ayala, K. Morokuma, G. A. Voth, P. Salvador, J. J. Dannenberg, V. G. Zakrzewski, S. Dapprich, A. D. Daniels, M. C. Strain, O. Farkas, D. K. Malick, A. D. Rabuck, K. Raghavachari, J. B. Foresman, J. V. Ortiz, Q. Cui, A. G. Baboul, S. Clifford, J. Cioslowski, B. B. Stefanov, G. Liu, A. Liashenko, P. Piskorz, I. Komaromi, R. L. Martin, D. J. Fox, T. Keith, M. A. Al-Laham, C. Y. Peng, A. Nanayakkara, M. Challacombe, P. M. W. Gill, B. Johnson, W. Chen, M. W. Wong, C. Gonzalez, and J. A. Pople, Gaussian, Inc., Pittsburgh PA 2003. 

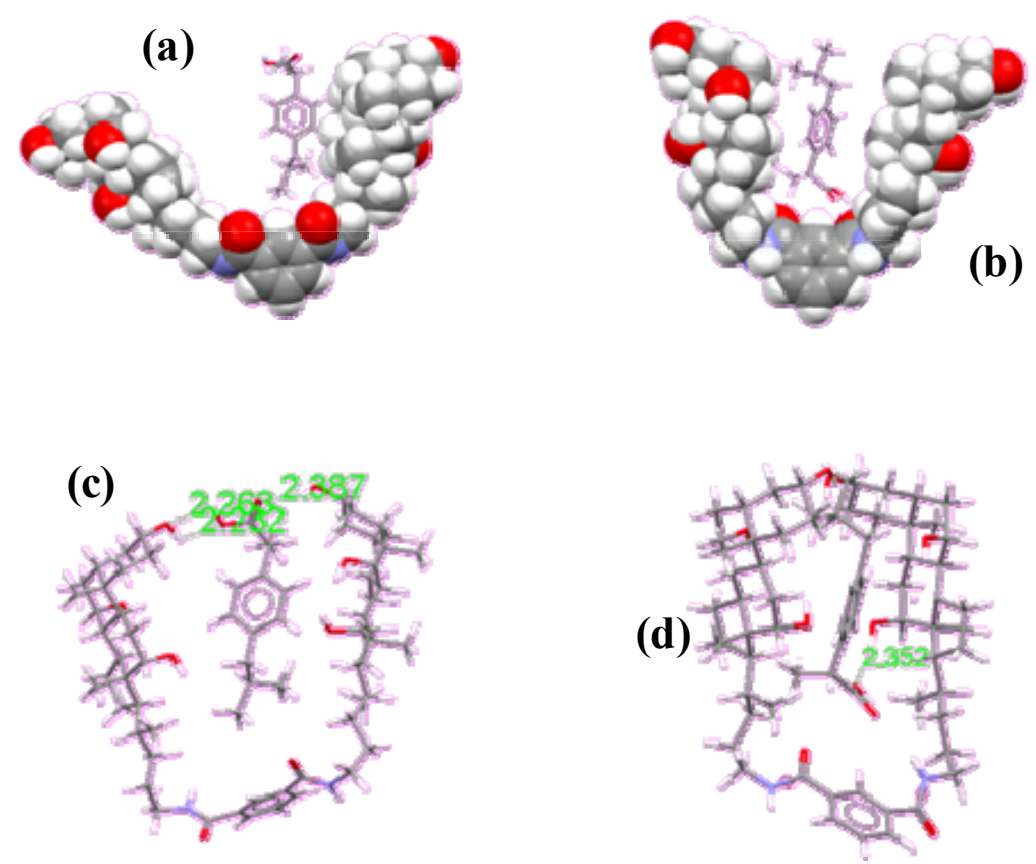

Figure 3.- Different AM1 optimized conformations for the complexes of $\boldsymbol{c}$ - $2 \boldsymbol{C}_{24}$-isoph (host) with ibuprofen (guest). (a) cleft-type conformation with opposite $\beta$ faces in the steroid residues and the iso-propyl group of ibuprofen pointing to the bridge, (b) cleft-type conformation with opposite $\beta$ faces in the steroid residues and the carboxylic acid group of ibuprofen pointing to the bridge, i.e, in a disposition inverted respect to (a). (c) and (d) imply cleft-type conformation with $\alpha$ faces opposite in the steroid residues and the arrangements of (a) and (b), respectively, for the guest. Hydrogen bonds have been drawn.

Table 1.- Results on the calculations performed for the hosts (c-2C $C_{24}-i s o p h$ and $\left.c-2 D C_{24}-i s o p h\right)$, the guest (ibuprofen) and the complexes (see text).

\begin{tabular}{|c|c|c|c|c|}
\hline Molecule & Identifying & Structure & AM1 energy / ${\mathrm{kcal} \cdot \mathrm{mol}^{-1}}^{-1}$ & $\Delta \mathrm{E} / \mathrm{kcal} \cdot \mathrm{mol}^{-1}$ \\
\hline$c-2 C_{24}$-isoph & $I$ & extended & -478.2 & - \\
\hline$c-2 C_{24}$-isoph & II & $\alpha$ faces opp. & $\begin{array}{ll}-479.8 \\
\end{array}$ & - \\
\hline$c-2 C_{24}$-isoph & III & $\beta$ faces opp. & -480.3 & - \\
\hline Ibuprofen & ibu & & -103.0 & - \\
\hline complex & C1 & Figure 3.a & -585.4 & $\mathrm{E}_{\mathrm{C} 1}-\mathrm{E}_{\mathrm{III}}-\mathrm{E}_{\mathrm{ibu}}=-2.1$ \\
\hline complex & $C 2$ & Figure 3.b & -588.8 & $\mathrm{E}_{\mathrm{C} 2}-\mathrm{E}_{\mathrm{III}}-\mathrm{E}_{\mathrm{ibu}}=-5.5$ \\
\hline complex & C3 & Figure 3.c & $\begin{array}{l}-593.9 \\
-1\end{array}$ & $\mathrm{E}_{\mathrm{C} 3}-\mathrm{E}_{\mathrm{II}}-\mathrm{E}_{\mathrm{ibu}}=-11.2$ \\
\hline complex & C4 & Figure 3.d & -593.6 & $\mathrm{E}_{\mathrm{C} 4}-\mathrm{E}_{\mathrm{II}}-\mathrm{E}_{\mathrm{ibu}}=-10.9$ \\
\hline$c-2 D C_{24}$-isoph & $I$ & extended & -393.5 & - \\
\hline$c-2 D C_{24}$-isoph & II & $\alpha$ faces opp. & -395.5 & - \\
\hline$c-2 D C_{24}$-isoph & III & $\beta$ faces opp. & $\begin{array}{l}-394.9 \\
-1\end{array}$ & - \\
\hline complex & $C 1$ & Figure 4.a & -501.0 & $\mathrm{E}_{\mathrm{C} 1}-\mathrm{E}_{\mathrm{III}}-\mathrm{E}_{\mathrm{ibu}}=-3.1$ \\
\hline complex & $C 2$ & Figure $4 . b$ & -502.0 & $\mathrm{E}_{\mathrm{C} 2}-\mathrm{E}_{\mathrm{III}}-\mathrm{E}_{\mathrm{ibu}}=-4.0$ \\
\hline complex & C3 & Figure 4.c & -507.4 & $\mathrm{E}_{\mathrm{C} 3}-\mathrm{E}_{\mathrm{II}}-\mathrm{E}_{\mathrm{ibu}}=-8.9$ \\
\hline complex & C4 & Figure 4.d & -506.3 & $\mathrm{E}_{\mathrm{C} 4}-\mathrm{E}_{\mathrm{II}}-\mathrm{E}_{\mathrm{ibu}}=-7.8$ \\
\hline
\end{tabular}


The greatest energy of stabilization in complexes comes from the formation of hydrogen bonds, i.e., when the steroid branches of the dimer host have their hydrophilic $\alpha$ faces are confronted to each other (C3 and C4, see also Figure 3). In C3 the carboxylic acid group of ibuprofen acts as a donor towards the hydroxyl group at position 3 of the steroid moiety in both dimers. However, in C4 the hydrogen bond is established between the carboxylic acid group of ibuprofen and the hydroxyl group at position 12 of the steroid moiety of $c-2 C_{24}$-isoph. In the case of derivative with deoxycholate residues, $c-2 D C_{24}$-isoph, the hydrogen bond takes place between the same hydrogen bond donor and the amide group of the steroid residue, acting as acceptor. The greater inclusion of the guest in this last case can be the origin of the energy differences. The structural difference between the two dimers is the presence or not of the hydroxyl group at position 7, but it does not participate in the formation of hydrogen bonds with the guest. Therefore, this group has not any influence in the values of the calculated energies.
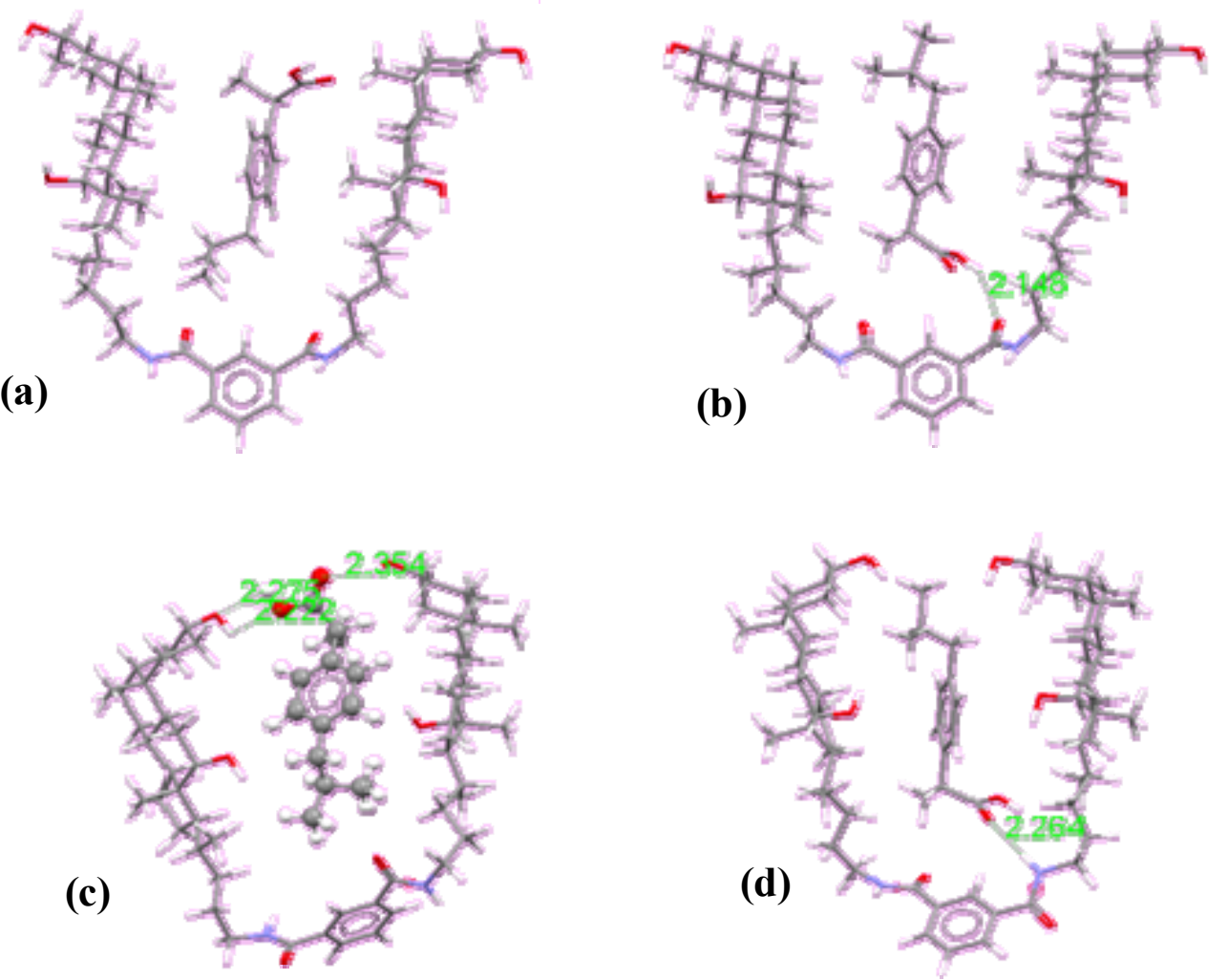

Figure 4.- Different AM1 optimized conformations for the complexes of $\boldsymbol{c}-\mathbf{2} \boldsymbol{D} \boldsymbol{C}_{24}$-isoph (host) with ibuprofen (guest). The captions for (a)-(d) are completely similar to those indicated in Figure 3. Hydrogen bonds have been drawn.

\section{Conclusions}


Several conformations of bile acid-based dimers (hosts) and ibuprofen (guest) in the formation of inclusion complexes of the cleft-type have been studied in gas phase by an AM1 semiempirical method (Gaussian 03). When the steroid branches of the dimers are confronted their $\alpha$ faces different structural consequences appear only when ibuprofen points its carboxylic acid group towards the bridge of the dimer. In the case of $c-2 C_{24}$-isoph a hydrogen bond is established between that group and the hydroxy group at position 12 of the steroid. However, for $c-2 D C_{24}$-isoph the hydrogen bonding is established with the amide group of the dimer.

Taking into account these results, we have synthesized these and other similar dimers (see another communication of the authors at ECSOC13) with the intention of carry out experimental studies.

Acknowledgments. Authors thank the Ministerio de Ciencia y Tecnología (Project MAT200404606) and the Xunta de Galicia (PGIDIT05PXIC26201PN) for financial support. 